\title{
The Quasi-paranoid Empathy of Healthcare Staff in a General- ized Covid-phobic Context in West Cameroon's Hospital Insti- tutions
}

\author{
Yannick Tamo Fogué ${ }^{1, *}$, Célestin Pierre Mboua ${ }^{2}$, Clémence Idriss Konfo Tcholong ${ }^{1}$ \\ ${ }^{1}$ Department of Psychology, University of Yaoundé 1, Cameroon \\ ${ }^{2}$ Department of Philosophy-Psychology-Sociology, University of Dschang, Cameroon \\ *Correspondence: yannicktam@yahoo.fr
}

How to cite this paper: Tamo Fogué, Y., Mboua, C. P., \& Konfo Tcholong, C. I. (2021). The Quasi-paranoid Empathy of Healthcare Staff in a Generalized Covid-phobic Context in West Cameroon's Hospital Institutions. Open Journal of Psychology, 1(1), 22 31. Retrieved from https://www.scipublications.com/journal/index.php/ojp/article/view/175
Received: November 02, 2021 Accepted: December 08, 2021 Published: December 09, 2021

Copyright: (c) 2021 by the authors. Submitted for possible open access publication under the terms and conditions of the Creative Commons Attribution (CC BY) license (http://creativecommons.org/licenses /by/4.0/).

\begin{abstract}
The present study raises the problem of empathy of caregivers vis-à-vis patients in a covid/post-covid context. It is based on the observation that health workers are increasingly invaded by excessive fear and persistence of COVID-19 contamination. This induces avoidance, a certain suspicion, persecution and indifference/coldness towards patients, and plunges them into a strong insidious emotional deficiency. These attitudes, which are significantly close to paranoid and phobic access, seem to gradually dominate therapeutic interactions within hospitals. Freudian and Rogerian psychoanalysis advocates empathetic/benevolent listening, positive consideration and unconditional acceptance of the patient as ethical and deontological indispensable principles for any therapeutic evolution. Thus, it is predicted that within hospitals, the current non empathetic attitudes of care towards patients have their origin in a generalized covid-phobic atmosphere that develops a quasi-dominant paranoia in caregivers. Using a subscale of caregiver's Covid-phobic quasi-paranoia, and the one of caregiver's empathy in a covid/post-covid context, the data were collected from 126 participants including 55 nursing assistants, 61 state-certified nurses and 10 doctors, chosen at random from the staff of three (03) health facilities in the city of Bafoussam, MIFI department, West Cameroon region, including one (01) public district medical center (CMA) and two (02) private hospitals (clinics). After analysis, the results obtained sufficiently demonstrate that within the health institutions of West Cameroon, the higher the professional level of the caregiver, the more the severity of his quasi-paranoid covid-phobic accesses is significant, and the less he expresses an authentic empathy towards the patients who arrive at the hospital. This implies that in this period of health crisis, caregivers must reinvest in a real function of providers of affectivity and relay of empathy at the bedside of the patient both in hospital and outpatient. Thus, a real systematical vaccination operation may insure their total immunity and better reduce their quasi-paranoid empathy in this generalized Covid-phobic context.
\end{abstract}

Keywords: Empathy, Covid-phobic quasi-paranoia, Nursing staff, Hospital institutions, Covid-19

\section{Introduction}

COVID-19 has plunged the entire planet into one of the most insidious health crises of the present millennium. It has a significant impact on life in general and specifically on human relationships. In health institutions, interactions between caregivers and caregivers, caregivers and patients, patients and patients are at the forefront. These are collective or individual situations for therapeutic purposes that, due to interactivities and human inter-exchanges, would expose more to the pandemic. Currently, all societies in the world are fatally affected [1] and all activities (educational, economic, health ...) empathize significantly. Thus, the adaptation strategies developed, including regular hand washing (with running water and soap) and the permanent use of disinfectants (such as hydro- 
alcoholic gel), physical distancing and the wearing of masks [2], seem to have systematically disrupted and altered uses, lifestyles and interpersonal relationships. The rhythms of life are no longer the same. Indeed, several governments around the world initially temporarily closed several social services and imposed a general or partial lockdown on their populations [3]. Currently, the announcement of the institutional requirement of tests and / or the anti-covid vaccine as a vignette of access to various services, amplifies the emergence of an almost deadly perception of the disease, plunging almost everyone into a generalized mistrust of the other. Especially in situations involving anyone symptomatically presenting discomfort (both somatic and psychic or both) and those apparently healthy. Family environments, religious, educational and hospital institutions, as well as other settings where individuals evolve, are strongly immersed in this phobic obsession against a background of reflex and daily aversion to the other, perceived a priori as potential contaminator to COVID-19.

In view of the current relaxation in the observance of barrier measures and the almost galloping resurgence of cases recorded in hospitals, there is a sharp upsurge in delirium of interpretation and suspicion, associated with avoidance and hyper-vigilance behaviors that invade almost all healthcare staff. This has a strong impact on caregiver-patient contacts/interactions, altering any emotional investment or counter-investment that should underpin therapeutic relationships. Indeed, the exchanges between patients who go to hospitals and the caregivers they meet there are driven by disproportionality in the valences of emotions, feelings and affects that are essential to the quality of reception, listening, comfort, consultation, diagnosis and care offered in this period of health crisis [4]. This is a context where phobic reactions supported by the excessive fear of COVID-19 contamination are widespread and growing [5]. This quasi-paranoia that dominates the daily life of the caregiver as well as a doctor, or even of any health personnel, seriously calls into question the quality of empathy ethically and ethically essential to the success of any therapeutic relationship within hospitals.

\subsection{Problematic}

In psychoanalytic practices, an indispensable place has always been given to empathy, apprehended according to Freudian logic as a mirror through which every patient perceives the reflection of his own image (self-image). It intervenes globally as a transpositive attitude of oneself in the thought, feelings, affects, emotions, actions of others (therapist) [6].This facilitates in the subject in a situation of physiological or psychopathological suffering a harmonious agreement between his self and his total experience, which he integrates by feeling the positive consideration and unconditional acceptance of himself by a therapist or a caregiver (accompanist) and by experiencing similar feelings towards himself. There is a strong correlation between the empathetic attitude/aptitude of the therapist/caregiver and the triggering of cathartic verbalization that disposes his patient to a healthy arity [7].In this logic, by approaching it under the prism of imitation and projective identification, psychoanalysis places listening at the center of empathy (empathic listening), as a means of hearing, understanding and feeling in the other what although he feels, does not hear and does not understand himself. Thus, Brunel and Martiny [8] states that "Freudian empathy is expressed essentially by speech, by listening to the verbal, and the paraverbal, the device of the couch allowing little observation of mimo-posturo-gestuality and therefore a large part of the non-verbal (mimics, sounds, body language ...)". This gives it an immense power of healing (evolution/remission), its appearance as a mirror for the soul, which through the word frees others, allows it to put words on its ills, and leads it to salutary recovery. This psychoanalytic reflexive dynamic gives empathy the mission of capturing the affective experiences of others, in particular the patient, by "resonance with the emotions and memories of an embodied subject" [9]. What Fonagy [10] inscribes in a process of mentalization and representation/conception of the mental and anatomo-physiological states that animate his daily non adaptations. 
The anti-COVID-19 measures that characterize the deep and current realities of the caregiver/patient relationship rather inhibit, in a fundamental way, the innate or phylogenetic needs for care, tenderness, affection, attention of patients admitted to hospitals. However, the positive consideration of the patient, his unconditional acceptance by his caregiver, associated with an active and manifest benevolence should constitute in any healing process, an identifying and transferential lever for his evolution [8].However, the authentic evolution that leads to beneficial recovery being dependent on the quality of the caregiver's responses to the empathetic listening needs of the patient, plunges the therapeutic relationship into exchanges of emotion, feeling and affect from the first contacts between the two [11]. In this period of health crisis, the caregiver seems to realize the heaviness of his function as a provider of affectivity or relay in the acts of care at the bedside of the patient both in hospitalization and outpatient. But out of irrational, excessive and pervasive fear of COVID-19 contamination [12], hospital care is paradoxically limited to the administration of active ingredients or physio-therapeutic molecules/drugs. However, there is a persistent indifference/coldness among healthcare staff, which plunges patients into a strong insidious emotional deficiency and leads to health care failures that are increasingly recorded in hospitals. Certainly healing needs a certain physio-therapeutic technical platform, but it requires more an emotional gift of self, tenderness, attention, affection, in short empathy for the patient [13, 14].Thus, the anti-COVID-19 measures make it possible to re-examine the quality of empathy in the therapeutic mobilization of health personnel, by placing any caregiver in front of his or her ability to listen, guess, interpret and understand the solicitations, needs, discomforts of the patient/ patient and to respond to them in an adapted and adequate way.

The restriction of emotional contact imposed by the hyper-observance of barrier measures such as confinement, the limitation of movement and visits to spaces, would have contributed to considerably degrade the caregiver-patient relationships in hospitals. However, psychoanalytic approaches require from the caregiver, a positive consideration and an unconditional acceptance of the helped or the patient/ patient, in order to understand him and bring him to understand himself, then develop his ability to renew and actualize himself, whatever the severity of his physiological discomfort and his existential phenomenological experience [15]. This seems consistent only if during the process of patient care, the caregiver frees himself from the anxio-pathogenic, phobic dimension of his context. This process requires a strong capacity to surpass oneself, to understand the exact nuance of the emotions that accompany the patient's experience, and to respond to them in a benevolent and empathetic way [8].In this covid/post-covid period, we paradoxically note a persistent displeasure of caregivers to get in touch with the treated. This induces a growing reluctance of the latter to attach themselves to the former, whether one is in hospitalization or outpatient. This seems to compromise the dynamics of clinical support, theoretically presented as the keystone of investments/counter-investments, transfers/counter-transfers, and especially commitment/adherence in any patient [16]. Especially at a time when the prevalence and severity of anxio-depressive experience among healthcare staff in Cameroonian hospitals have increased because of COVID-19 [4]. Indeed, we observe more and more persistence of fear, avoidance, suspicion, persecution or indifference that they develop towards patients. Attitudes that are significantly close to schizo-paranoid or schizotypical and phobic attacks, and seem to gradually dominate caregiver-patient relationships, profoundly questioning their capacities and resilience mechanisms in the context of a health crisis. Hence the problem of relational or socioemotional balance of patients with their caregivers, who are increasingly invaded by a generalized covid-phobic atmosphere within hospitals, where a quasi-paranoia now seems to plunge their attitudes of care into a certain antipathy. 


\subsection{Research hypothesis}

This study is based on the assumption that: Within hospitals, current non empathetic attitudes of care towards patients stem from a generalized/invasive covid-phobic atmosphere that develops a dominant quasi-paranoia in caregivers.

\section{Method}

\subsection{Participants}

The sampling population of this study consists of one hundred and forty-six (146) medical staff identified in one (01) public district medical center (CMA) and two (02) private hospitals (clinics) in the city of Bafoussam, MIFI division, West-Cameroon region. Both public and private medical structures were chosen just to make the two sectors of Cameroon's hospital system to be better represented in the research. Thus, the formula of Krejcie and Morgan [17] $\left(S=\frac{X^{2} N P(1-P)}{d^{2}(N-1)+X^{2} P(1-P)}\right)$, determined the sample size. Indeed, with a confidence level $X=95 \%$ (standard value $(\mathrm{d}=1.96)$ ), the size of the sampling population $\mathrm{N}=146$, the proportion $\mathrm{P}=0.5$ and the margin of error $\alpha=5 \%$ (standard value of .05 ), 126 participants were selected as the sample of the study. This seemingly small size seemed suitable for this research, given the reluctance of the nursing staff. With stratified random sampling associated with a proportionality coefficient $\mathrm{k}=\frac{126}{146}=0.86,55$ participants were provided nursing assistants $(\mathrm{n} 1=63 \times 0.86=55.18), 61$ state-certified nurses $(\mathrm{n} 2=71 \times 0.86$ $=61.06)$ and 10 doctors $(\mathrm{n} 3=12 \times 0.86=10.32)$, randomly selected from the staff of three (03) health facilities. The inclusion criteria were based on the following conditions: Be an agent of the State (civil servant or contractor) for those investigated in the public hospital, or have a permanent employment contract for those of private hospitals; Have at least five (05) years of seniority within the hospital; Do not combine his function as a caregiver (for nursing assistants and nurses) or consultant (for doctors) with any administrative function; Have never tested positive for Covid-19 and have not been vaccinated against it, because this history would influence the anxious attacks [18] that underlie the quasi-paranoia Covid-phobic in the individual.

\subsection{Material and procedure}

This research is a study of dependence between the generalized Covid-phobic context in hospitals and the empathy of healthcare staff who are increasingly almost paranoid towards outpatients or inpatients. Based on a quantitative approach, it is descriptive in purpose and its data collection design is based on independent groups (nursing assistants, nurses, doctors). The data collection instrument used is a questionnaire constructed for the specific needs of this study. It is composed of two subscales namely: a subscale of evaluation of the quasi-paranoid Covid-phobic of the caregiver, built from the descriptive traits of paranoid accesses defined in the DSM-5 [19]; and a subscale for assessing caregiver empathy in a covid/post-covid context, constructed from items from the empathy and emotional contagion scale of Favre, Joly, Reynaud and Salvador [20].

Each participant who received a copy of the instrument was randomly selected, ensuring compliance with all inclusion criteria. In doing so, a mini-questionnaire of identification of the subject was first administered to collect biographical information on him in particular, his sex, his age, his place of residence in the city, his family situation (marital status, number of children), his link or his life with his family (parents, siblings and collaterals), his status (agent of the state for the public or permanent for the private) and his seniority in the hospital, the non-administrative function and his medical history (duration of his last Covid-19 test, his current serology vis-à-vis Covid-19, if he has already been diagnosed Covid-positive, if it has already been vaccinated against Covid-19). This also helped to stabilize/standardize participants at the time of counting. After identification, 
each participant was subjected to the initiation which consisted of administering the two subscales of the study. Thus:

The participant first filled in the subscale of the caregiver's Covid-phobic quasi-paranoia. It was composed of ten (10) items, coded on a 5-point Likert scale $(1=$ Very strongly disagree; 2 = Medium disagreement; 3 = No opinion; 4 = Somewhat agree; 5 = Very strongly agree) and having such significant psychometric reliability (Global internal coherence or Cronbach alpha $(\alpha)=.91$; fidelity (rtest-re-test) $=.69$; KMO index $=.87$; Khi 2 approx $=764.28$ ). His items are as follows: 1) I have the impression and without sufficient reason that patients want to harm me, deceive me and launch Covid-19; 2) I am concerned about unjustified doubts about the Covid-negativity of people in the hospital; 3) I am reluctant to approach, touch, give time to the patient, for unjustified fear of contracting Covid-19 on him; 4) I discern threatening concealments of people who manifest symptoms of Covid19 in innocuous attitudes and behaviors; 5) I hold a grudge against the patient and his caregivers (sick guards), if I suspect that they have approached me when they are not vaccinated and do not have a mask; 6) I perceive threats of contamination around me in the hospital, when it is not apparent to others, and am quick to angrily push back the patient I suspect; 7) I permanently question the Covid-negativity of any person, caring for as a patient in the hospital; 8) With the persistence of Covid-19, I recognize myself more and more having an invasive suspicious attitude towards any patient who arrives or stays in the hospital; 9) I am driven by an irrational and pervasive fear of being infected by patients; 10) I have a hard time sharing the same space as a patient because I always feel like they have Covid-19.By way of rating, a score between 0 and 16 indicates a mild quasiparanoia Covid-phobic, a score between 17 and 32 indicates moderate quasi-paranoia Covid-phobic and a score between 33 and 50 indicates severe quasi-paranoia Covid-phobic, in the caregiver.

Then, the participant filled in the caregiver's empathy subscale in a covid/post-covid context. Composed of fifteen (15) items with dichotomous coding ( 1 = Does not apply to me; 2 = Applies to me), it had satisfactory metrological qualities (Global internal coherence or Cronbach alpha $(\alpha)=.89$; fidelity (rtest-re-test) $=.72 ; \mathrm{KMO}$ index $=.83$; Khi 2 approx $=843.46$ ). His items are as follows: 1) When I see a patient or a seemingly suffering person that I do not know, alone, while there are people near him who are not interested in him, I try to feel whether or not it suits him to be alone; 2) It's nice for me to see a patient laughing because I tell myself that he is satisfied with the care he is given; 3 ) The demonstrations of affection in front of the patients most often do not annoy me; 4) I have difficulty announcing a misdiagnosis to patients because it gives me too much trouble for him; 5) When I see a patient crying or sad or worried or melancholy it makes me lose my means; 6) The show of affection towards a patient makes me want to live a lot of moments like this;7) Seeing a patient or their caregiver (sick guard) crying with joy following a favorable outcome or healing makes me want to cry with him; 8) I see patients every day, but it is easy for me to deeply experience a patient's feelings; 9) When I see a patient who has psychological problems, I listen to him if it feels good to talk about it;10) When I see a patient or a seemingly suffering person whom I do not know, alone, while there are people near him who are not interested in him, I always approach or touch him to assist him; 11) When I see a patient crying or sad or worried or melancholy it makes me sensitive; 12) When colleagues around me get agitated or panic over an emergency, I don't stop myself from agitating too;13) When a patient near me is very happy, I easily become happy with him; 14) It is painful for me to announce an unfavorable or vital prognosis or a serious or chronic illness to a patient; 15) It is easy for me to be preoccupied with a patient's illness until I am anxious and worried about him. A score between 0 and 19 indicates absent or weak empathy and a score between 20 and 30 indicates present or strong empathy in the caregiver. 


\section{Result}

\subsection{Descriptive analysis of the main variables of the study}

The data collected having been analyzed with the statistical software SPSS-21, they presented a moderate level of quasi-paranoid covid-phobic access, with an overall low level of empathy among the participants taken as a whole. Table 1 presented the distribution of the average scores and their standard deviations obtained at the subscales for measuring these different variables, according to the occupational level of the caregivers.

Table 1. Description of the quasi-paranoid covid-phobic trends and the level of empathy in covid/postcovid context of caregivers according to their statuses

\begin{tabular}{cccccc}
\hline \multirow{2}{*}{\begin{tabular}{c} 
Professional level of $\begin{array}{c}\text { Level of quasi-paranoid covid- } \\
\text { the caregiver }\end{array}$ \\
\cline { 2 - 5 }
\end{tabular}} & $\begin{array}{c}\text { Learegiver's level of empathy } \\
\text { phobic access of the caregiver }\end{array}$ & $\begin{array}{c}\text { Frequency } \\
\text { with patients }\end{array}$ & (N) \\
\cline { 2 - 5 } & Average & Std.Deviation & Average & Std. Deviation & \\
\hline Doctors & 28.2000 & 8.02496 & 17.2000 & 2.48551 & 10 \\
Nurses & 24.3607 & 7.07115 & 17.6230 & 2.60233 & 61 \\
Nursing assistants & 21.7636 & 7.18528 & 18.7091 & 3.33151 & 55 \\
Total & 23.5317 & 7.37530 & 18.0635 & 2.97118 & 126 \\
\hline
\end{tabular}

It was noted that within health institutions, the higher the professional level of the caregiver, the more significant the severity of his quasi-paranoid covid-phobic accesses. On the other hand, doctors express less empathy towards patients, followed respectively by nurses and nursing assistants who still show them a relatively low empathy. It is important to remember that a score between 0 and 16 indicated mild covid-phobic quasiparanoia, while those between 17 and 32 or 33 and 50 indicated moderate or severe attacks respectively. However, scores between 0 and 19 or 20 and 30 demonstrated low or strong empathy in caregivers, respectively. The table above describes that the more the caregiver is expected to set an example in terms of ethics and deontology towards the patient, and this for having received significant training in terms of duration and quality, the less resilient he is to the fear and anxiety induced by the persistence of the COVID-19 crisis. Indeed, the tendencies of avoidance, suspicion, persecution or indifference towards patients are more significant in doctors followed by nurses, than in nursing assistants.

\subsection{Inferential analysis of the predictive and comparative links of the study.}

The inferential analysis of the data collected revealed significantly predictive relationships between the occupational level of the participants and each of the main variables of the study (Table 2). This cause-and-effect relationship was also noted between the two variables studied (Table 3). However, an analysis of variance highlighted variations in levels of quasi-paranoid covid-phobic access and empathy between the three groups of participants (doctors, nurses, nursing assistants), as well as within each group. 
Table 2. Dependence between the caregiver's professional level and his level of quasi-paranoid covid-phobic access, as well as his level of empathy towards patients

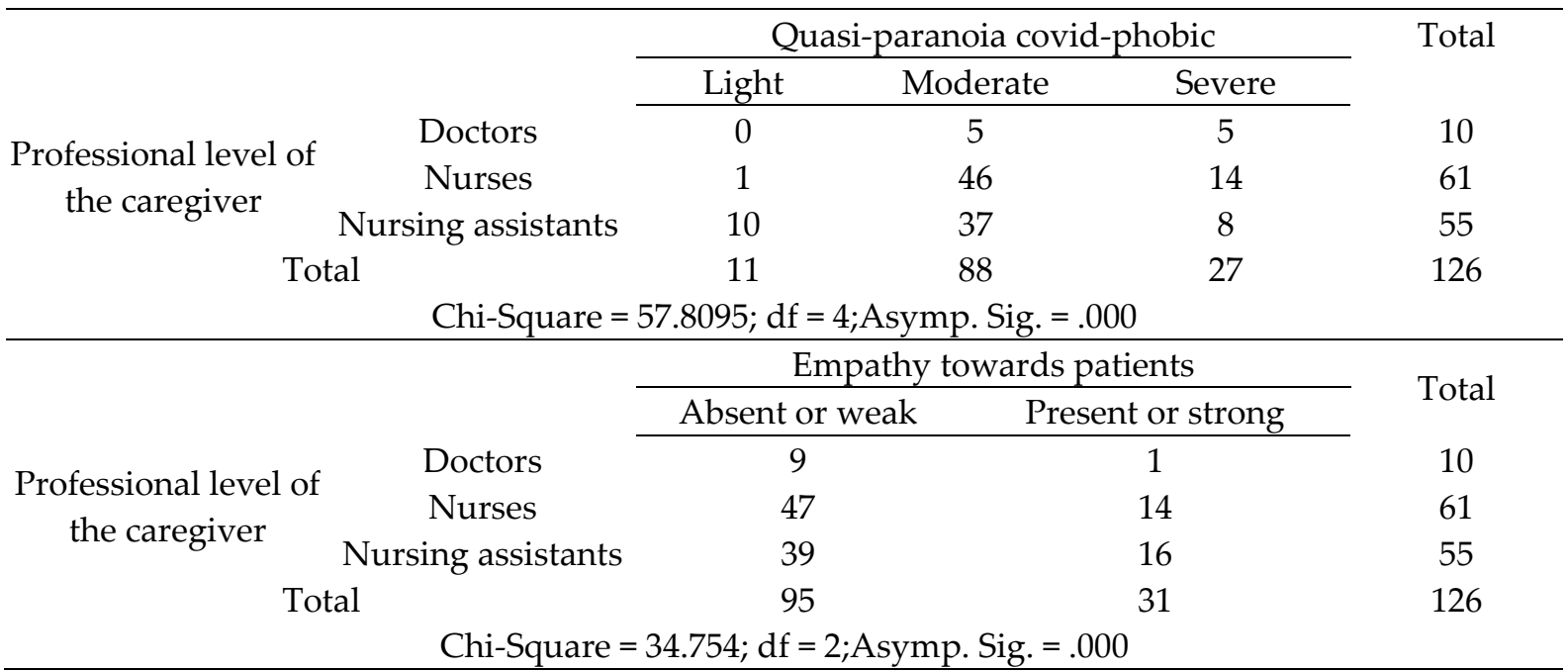

It has been noted that the severity of quasi-paranoid covid-phobic bouts among healthcare staff is significantly a function of their high level of vocational training (X2(126) $=57.81 ; \mathrm{p} .=.00)$. Indeed, all the doctors who participated in the present study are more animated by a quasi-paranoia covid-phobic either moderate (50\%), or severe (50\%). As for nurses, respectively $7 \%, 75 \%$ and $18 \%$ have more mild, moderate or severe quasi-paranoia covid-phobic. However, nursing assistants mostly have mild and moderate accesses (18\% and $67 \%$ ) than severe (14\%). With respect to their levels of empathy towards patients, there was a significant drop as the caregiver's level of training increased $(X 2(126)=34.75$; p. $=.00$ ). Indeed, $90 \%$ of doctors, $77 \%$ of nurses and $71 \%$ of caregivers show only slightly or almost no empathy towards patients.

Table 3. Dependence between quasi-paranoia covid-phobic and healthcare workers' empathy towards patients

\begin{tabular}{|c|c|c|c|c|}
\hline \multirow{5}{*}{$\begin{array}{l}\text { Quasi-paranoia } \\
\text { covid-phobic }\end{array}$} & & \multicolumn{2}{|c|}{ Empathy towards patients } & \multirow[t]{2}{*}{ Total } \\
\hline & & Absent or weak & Present or strong & \\
\hline & Light & 4 & 7 & 11 \\
\hline & Moderate & 70 & 18 & 88 \\
\hline & Severe & 21 & 6 & 27 \\
\hline \multirow{2}{*}{\multicolumn{2}{|c|}{ Total }} & 95 & 31 & 126 \\
\hline & & $85 ; \mathrm{df}=2 ;$ Asymp & .000 & \\
\hline
\end{tabular}

This table actually shows that within hospitals, the current unsympathetic attitudes of care towards patients have their origin in a generalized/invasive covid-phobic atmosphere that develops a quasi-dominant paranoia in caregivers. In other words, the more severe the covid-phobic quasi-paranoid access is in the caregiver, the less empathy they show towards patients $(\mathrm{X} 2(126)=55.57 ; \mathrm{p} .=.00)$.Indeed, while up to $64 \%$ of caregivers who have mild covid-phobic quasi-paranoia show them strong empathy, $80 \%$ and $78 \%$ of those who have moderate and severe access to it respectively show low empathy towards patients. 
Table 4. Analysis of intra- and inter-group variation in the level of quasi-paranoid covid-phobic access and the level of empathy of health workers in the covid/postcovid context

\begin{tabular}{ccccccc}
\hline & & Sum of Squares & Df & Mean Square & F & Sig. \\
\hline $\begin{array}{c}\text { Variations in the caregiver's } \\
\text { level of quasi-paranoid covid- }\end{array}$ & Between Groups & 431.780 & 2 & 215.890 & 4.170 & .018 \\
phobic access & Within Groups & 6367.593 & 123 & 51.769 & & \\
\hline $\begin{array}{c}\text { Variations in the caregiver's } \\
\text { level of empathy towards pa- }\end{array}$ & Between Groups & 6799.373 & 125 & & & \\
tients & Within Groups & 1061.273 & 123 & 8.628 & & \\
& Total & 1103.492 & 125 & & & \\
\hline
\end{tabular}

From the table above, the analysis of variance between doctors, nurses and caregivers, as well as within each group revealed that hospital caregivers develop more moderate covid-phobic quasi-paranoid access, with more significant within groups variations than intergroup $[\mathrm{F}(126)=4.17 ; \mathrm{p}<.02]$. For the level of empathy of the caregiver who was more absent or weak towards patients, the same variations were noted, that is, more intragroup than intergroup in the participants of the present study $[\mathrm{F}(126)=2.45 ; \mathrm{p}<.02]$.

\section{Discussion}

This research confirms that beyond the interferences noted in the scores obtained at the two subscales administered to participants, there is a significant predictive link between the professional level of caregivers and the severity of the quasi-paranoid covidphobic accesses, then their level of empathy developed towards patients in a covid/postcovid context. The results obtained do not reveal a difference between the public and private caregivers, because the objective wasn't to analyze the variation of the two variables among the different sectors of Cameroon's hospital system. Therefore, they sufficiently demonstrate that within the health institutions of West Cameroon, the higher the professional level of the caregiver, the more the severity of his quasi-paranoid covid-phobic accesses is significant and the less empathy he expresses towards the patients who arrive at the hospital. This corroborates with some work that has shown that corona virus disease (COVID-19) can cause people to experience significant stress, anxiety, and even depression [12]. From a factorial point of view, this seems to be linked to the deadly image that is persistently presented of this pandemic [21], which induces widespread anxiety and fear in any social environment. Thus, this health crisis has significantly increased the prevalence of anxio-depressive attacks among healthcare workers in general [22], particularly those in hospitals and health centers, which are permanently driven by the irrational, excessive and pervasive fear of COVID-19 contamination and death [13].

According to Mboua, Nguépy Keubo and Ngueuteu Fouaka [4], there is a rate of $41.8 \%$ anxiety, $42.8 \%$ depression, $14.73 \%$ anxio-depressive co-morbidity in Cameroon, with respectively $8.2 \%$ and $3.3 \%$ of major depressive disorder and adaptation among health workers, as well as a high susceptibility among those aged 30 to 39 years. Hence the attitudes that the present study describes among caregivers, which are significantly close to schizoid, paranoid and phobic accesses. Indeed, the persistence of fear, avoidance, suspicion, persecution or indifference that they develop towards patients, is the manifestation of what this research has described as quasi-paranoia covid-phobic. It is gradually dominating caregiver-patient relationships within hospitals and is profoundly questioning the mechanisms of resilience and the quality of empathy of caregivers in the covid/post-covid context. But by apprehending empathy as the ability to let oneself be penetrated by the discourse of the other, Pagès [23] already organized it around a benevolent and neutral listening to others, refraining from judging, directing, criticizing, orienting, analyzing/interpreting his discourse/experience, and influencing his process of self-analysis or selfcriticism. In this wake, Rogers [24] advocated "non-directivity", and "non-judgment", in- 
sisting on an "authenticity" on the part of the caregivers/caregivers, that is, to feel the feelings/emotions of the helped (the patient or the patient) "as if" one were him, without however straying into his experience. This inscribes empathy in a process of empowerment of the other, focusing on his experience that he lives as "nonsense" and source of devaluation, conflict between the real self and the ideal self, and narcissistic wound. It channels the cognitive-emotional investments of any patient towards socio-adaptive autonomy through effective support, where one enters as best as possible into his perceptual world.

\section{Conclusion}

Within hospitals, the empathy of caregivers should be part of an inter-actionist logic of the link to any patient, whether outpatient or inpatient. Thus, the therapeutic interaction between caregiver and patient must in all circumstances be animated by emotions/feelings, imaginations/cognitions and reciprocal capacities of anticipation/action on a possible somato-psychic complication in the patient. The perceived dangerousness of COVID-19 should therefore base therapist-patient relationships on an identification process where the caregiver, whether a doctor, nurse or nursing assistants, is a provider of affectivity [25]. This ethically and ethically inherent posture of any health worker involves the analysis of the patient's speeches, actions and thoughts, as well as his or her deep needs. This exercise allows the caregiver to experience/feel by remaining himself, the exact nuance of the emotions that animate the patient [26]; to grant him a benevolent listening, while giving him the floor to put the words on his evils, and to free himself from the anxious and psycho-pathogenic dimensions of his suffering. Moreover, according to the current psychoanalytic literature [8], the empathy of the caregiver in the hospital must take on active dimensions such of: observe, listen, perceive, discern, deduce, infer, grasp, understand, interpret the suffering and the authentic experience of the patient. That empathy must also take on passive dimensions such of: Passive, that is to say, provoke in the patient, an emotional contagion, a projection, an identification, a reflection, an inner imagination of oneself, in the image of his positive consideration by his caregiver. The principal motor of the empathy is to adopt a gesture, a mimicry, a body imitation, a posture and movements that trigger a real cathartic verbalization/attitude in the patient. This indispensable constitutive faculty of therapeutic interaction must be particularly restored by healthcare staff in hospitals, although it seems complex to deploy it for all patients and in all situations [27]. Especially in this period of health crisis where being available, overcoming one's own self (one's reality) or one's almost paranoid covid-phobic experience and unconditionally accepting one's patient seems necessarily required to bring him a salutary recovery. Therefore, to significantly reduce the quasi-paranoid empathy of caregivers in this generalized Covid-phobic context in which they actually move a real systematical vaccination operation has to be lunched toward all the hospital workers, in other to insure their total immunity vis-à-vis the COVID-19.

\section{References}

[1] Andrianarison, F. \& Nguem, B. E. (2020). Potential socioeconomic effects of COVID-19 in Cameroon: A summary evaluation. Yaoundé-Cameroun: PNUD.

[2] United Nations Cameroon (2020). Socioeconomic response plan of United Nations to the COVID-19. Yaoundé-Cameroun: United Nations Cameroon.

[3] Okouda, B. (2020). Impact of the COVID-19 on Cameroonian economy: Confinement or protectionism, beyond the urgency, and opportunity to realize the break of our economic model. Yaoundé: Cameroon's Analysis and Research Center of Economic and Social Policies.

[4] Mboua, C. P., Nguépy Keubo, F. R., \& Ngueuteu Fouaka, S. G. (2021). Anxiety and depression associated to the taking incharge of the CODID-19 on the health care workers in Cameroon. Psychiatric evolution, 86, 131-139. https://doi.org/10.1016/j.evopsy.2020.11.002.

[5] Niang, M., Cheikh Oumar, B.-A., Hathie, I., Tounkara, S., Sene, S. O., \& Ly, A. (2020). COVID-19 effects on the agricultural and rural families in Senegal. Dakar: Agricultural and Rural Prospective Initiative. http://www.ipar.sn, 
[6] Allport, G. W., \& Vernon, P. (1937). Studies in expressive moment. New York: Macmillan.

[7] Tordo, F. \& Binkley, C. (2016). Auto-empathy or the come about others in oneself: Definition and clinic of the virtual. Psychiatric Evolution, 2, 81, 293-308.

[8] Brunel, M.-L., \& Martiny, C. (2004). The concept of empathy before, during and after Rogers. Camerology, 473-500.

[9] Georgieff, N. (2008). The empathy today: At the crossover of neurosciences, psychopathology and psychoanalysis. The child psychiatry, 51 (2), 357-393.

[10] Fonagy, P. (2015). Mutual Regulation, Mentalization, and therapeutic Action: A Reflection on the Contributions of Ed Tronick to Developmental and Psychotherapeutic thinking. Psychoanalytic Inquiry, 35-4, 335-369.

[11] Maillard, B., Vinay, A., Rexand-Galais, F. \& Héry, C. (2019). Affective dependency and relational autonomy of the HIV infected adolescence. Child and adolescence neuropsychiatry, 67(2), 70-74.

[12] Huang, Y. \& Zhao, N. (2020). Generalized anxiety disorder, depressive symptoms and sleep quality during COVID-19 epidemic in China: a web-based cross-sectional survey. http://dx.doi.org/10.1016/j.psychrs.2020.112954.

[13] Cobb, A. (2019). Socio-emotional learning. Québec, Canada: CCED.

[14] Golse, B. (2008). Affective development. In Affective and intellectual child development (4 ${ }^{\text {th }}$ edit, Pp. 9-165). Paris: Masson

[15] Rogers, C. (2002). Helping relationship and psychotherapy (13 $3^{\text {th }}$ edit). Paris: ESF.

[16] Okah Efogo, F. \& Okah Atenga, M.-F. (2020). Cameroon's exchanges in Africa under the COVID-19 experience. In S. Moungou Mbenda \& V. Ondoua Biwole (Eds.), Epidemiology of the economy and confinement of the COVID-19 organization (Chap. 8, Pp. 127-142). Yaoundé: Yaoundé University Press.

[17] Krejcie, R. V, \& Morgan, D. W. (1970). Determining Sample Size for Research Activities. Educational and Psychological Measurement, 607-610.

[18] Health and social service of Québec (2019). Stress, anxiety and depressed associated to the corona virus COVID-19 disease. Québec: Québec Government

[19] American Psychiatric Association. (2013). Diagnostic and statistical Manual of Mental Disorders (DSM-5). United Nations: APA.

[20] Favre, D., Joly, J., Reynaud, C., \& Salvador, L.-L. (2009). Empathy, emotional contagion and splitting with emotions: Validation of a test to locate and help pupils at risk. European Review of Applied Psychology, 59, 3, 211-227.

[21] Lai, J. Man, S., Wang Y. et al. (2020). Factors associated with mental health outcomes among, health care workers exposed to coronavirus disease 2019. JAMA Netw Open, 2(3). http://dx.doi.org/10.1001/jamanetworkopen.2020.3976.

[22] Pappa, S., Ntella, V., Glannakas, et al. (2020). Prevalence of depression, anxiety and insomnia among health care workers during the COVID-19 Pandemic: a systematic review and meta-analysis. Brain Gehav Hummun. http://dx.doi.org/101016/j.bbi.2020.05.026.

[23] Pagès, M. (1963). Non directive orientation in psychotherapy. Social Psychology. Paris: Dunod.

[24] Rogers, C. R. (1975). Empathic: An unappreciated way of being. The counseling Psychologist, 5(2), 2-10.

[25] Bornstein, M. Lichtenberg, J. \& Silver, D. (1996). Interaction: Reflections on one-or-tow-person psychology. Psychoanalytic, 16, 1.

[26] Monestres, J.-L. (2011). Train oneself to develop empathy. Mental Health, 158, 76-80.

[27] Cungi, C. (2011). Therapeutic alliance and empathy. Mental Health, 158, 82-87. 